\title{
Expectativas e Sentimentos da Gestante em Relação ao seu Bebê ${ }^{1}$
}

\author{
Cesar Augusto Piccinini² \\ Aline Grill Gomes \\ Lisandra Espíndula Moreira \\ Rita Sobreira Lopes \\ Universidade Federal do Rio Grande do Sul
}

\begin{abstract}
RESUMO - A relação da mãe com seu bebê vai se constituindo desde o período pré-natal, e é influenciada pelas expectativas que ela tem sobre o bebê e pela interação que estabelece com ele. Esta primeira relação serve de prelúdio para a relação mãe-bebê que se estabelece depois do nascimento. O objetivo deste estudo foi investigar as expectativas e os sentimentos das gestantes em relação ao bebê. Participaram 39 gestantes primíparas, no último trimestre de gestação, com idades entre 19 e 37 anos. As gestantes foram entrevistadas individualmente e as suas respostas foram examinadas através de análise de conteúdo. Os resultados indicaram que as mães procuram, já desde a gestação, oferecer mais identidade ao bebê, atribuindo-lhe expectativas e sentimentos quanto ao seu sexo, nome, características psicológicas, saúde, além de interagirem com ele. Isto parece reverter em um investimento importante à constituição psíquica do bebê, além de possibilitar o exercício da maternidade.
\end{abstract}

Palavras-chave: gestação; expectativas; bebê.

\section{Pregnant Woman's Expectations and Feelings Regarding her Baby}

\begin{abstract}
The mother's relationship with her baby is constructed since the prenatal period and is influenced by her expectations regarding the baby and the interaction she establishes with him/her. This first relationship serves as a prelude of the mother-infant relationship established after birth. The aim of this study was to investigate the pregnant women's expectations and feelings regarding the baby. Thirty-nine primiparous pregnant women, in the last trimester of gestation, aged 19 to 37 , took part in this study. The pregnant women were individually interviewed and their answers were examined through content analysis. The results indicated that, since pregnancy, mothers try to give the baby more identity, holding expectations and feelings regarding his/her sex, name, psychological characteristics, health, besides interacting with him/her. This seems to constitute an important investment for the baby's psychic constitution, besides enabling mothering.
\end{abstract}

Key words: pregnancy; expectations; baby.

A gestação é um evento complexo, com mudanças de diversas ordens; é uma experiência repleta de sentimentos intensos que podem dar vazão a conteúdos inconscientes da mãe (Brazelton \& Cramer, 1992; Klaus \& Kennel, 1992; Raphael-Leff, 1997; Raphael-Leff, 2000; Soifer, 1980). A relação da mãe com seu filho já começa desde o período prénatal, e se dá, basicamente, através das expectativas que a mãe tem sobre o beb $\hat{e}^{3} \mathrm{e}$ da interação que estabelece com ele. Esta primeira relação serve de prelúdio para a relação mãe-bebê que se estabelece depois do nascimento e, portanto, merece ser melhor compreendida (Brazelton, 1987; Brazelton, 1988; Caron, 2000; Condom \& Corkindale, 1997; Müller, 1996; Stainton, 1985).

Diferentemente de qualquer outra relação de intimidade, nesta os indivíduos são quase que invisíveis um para o outro e,

1 Os autores agradecem o apoio do CNPq.

2 Endereço: Universidade Federal do Rio Grande do Sul, Rua Ramiro Barcelos, 1853/112, Porto Alegre, RS, Brasil 90035-003. E-mail: piccinini@portoweb.com.br

3 Embora o presente estudo trate do período da gestação e do feto, o termo bebê foi usado em grande parte do texto, por parecer mais adequado ao se referir ao significado que a mãe atribui ao filho ainda no útero. O termo feto é mais utilizado na literatura médica, mas parece não expressar adequadamente os sentimentos e as representações sobre o filho. Contudo, em algumas situações específicas fez-se necessário recorrer ao termo feto para não confundir o leitor. por isso, as expectativas formam a base da relação (RaphaelLeff, 1991). As expectativas da mãe em relação ao bebê originam-se de seu próprio mundo interno, de suas relações passadas e suas necessidades conscientes e inconscientes relacionadas àquele bebê (Maldonado, 1997; Raphael-Leff, 1997; Soulé, 1987; Szejer \& Stewart, 1997). Estas são mais freqüentes e intensas no segundo trimestre da gestação, que é o momento em que o feto, através dos movimentos, anuncia realmente sua existência. Depois do sétimo mês, o volume e a intensidade dessas expectativas tendem a diminuir, preparando, desta forma, o lugar do bebê real (Caron, Fonseca \& Kompinsky, 2000; Stern, 1997).

A literatura aponta repercussões tanto positivas quanto negativas da presença das expectativas da mãe para a maternidade, para o psiquismo do bebê e para a relação entre a dupla. Os aspectos positivos envolvem, principalmente, a necessidade de que o bebê seja investido de desejos e fantasias por parte da mãe para começar a existir enquanto ser humano. Os "ditos" e "não ditos" que precedem não só o nascimento, mas também a concepção do bebê são elementos que permitem a sua estruturação psíquica (Brazelton \& Cramer, 1992; Caron, 2000; Stern, 1997; Szejer, 1999; Szejer \& Stewart, 1997). A gestante parece ter um nível de relação próximo com o bebê quando ela consegue imaginá-lo, investir nesta imagem, ainda que esta provenha de ideais desejados (Raphael-Leff, 1991). As expectativas são consideradas negativas quando não há 
espaço para o bebê assumir sua própria identidade, isto é, quando a mãe não consegue aceitar a singularidade de seu filho e abandonar sua carga maciça de projeções (Brazelton \& Cramer, 1992; Caron \& cols., 2000; Szejer \& Stewart, 1997). Há ainda casos de gestantes que não conseguem investir no bebê nem esperar nada dele, por medo que a realidade não satisfaça seus desejos. Algumas outras atribuem ao bebê somente expectativas de insucesso e de morte, o que geralmente se revela não através de verbalizações e sim de sensações, pensamentos e intensas preocupações. Nestas situações, a mãe não consegue desvencilhar-se de suas próprias vivências negativas e a relação mãe-bebê fica comprometida (Raphael-Leff, 1991).

As expectativas se constituem, então, sobre o bebê imaginário que cada mãe constrói, e envolvem, principalmente, o sexo do bebê, o nome, a maneira como ele se movimenta no útero, e as características psicológicas que são a ele atribuídas (Szejer \& Stewart, 1997). O confronto deste bebê imaginário com o bebê real ocorre, com definição, após o nascimento; porém, atualmente, com o advento da ultra-sonografia obstétrica, alguns aspectos concretos do bebê podem ser conhecidos ainda durante a gestação (Caron, 2000; Gomes, 2003). Estes dados podem tanto incrementar as fantasias maternas, como também, desde já, antecipar algumas frustrações.

O sexo é um dos principais aspectos para se conhecer o bebê antes de seu nascimento (Grace, 1984), e por isso carrega muitos simbolismos (Szejer \& Stewart, 1997). Muitas gestantes desejam conhecer o sexo do seu bebê ainda na gestação (Fonseca, Magalhães, Papich, Dias \& Schimidt, 2000), principalmente aquelas que já têm filhos ou que estão diante de uma gravidez não planejada (Villeneuve, Laroche, Lippman \& Marrache, 1988). Sabe-se, ainda, que a razão para algumas gestantes não desejarem obter esta informação precocemente, é por não se sentirem preparadas para conhecer a verdade, e este saber antecipado passa a ser visto como uma violência (Szejer \& Stewart, 1997). Porém, sabese que mesmo não tendo conhecimento do sexo do bebê, os pais tendem a ter uma idéia interiormente formulada, uma identificação imaginária para o filho, mesmo que esta não coincida entre eles e nem tampouco seja verdadeira. Conhecer o sexo do bebê antes do nascimento possibilita reconhecê-lo de outra forma, podendo nomeá-lo e torná-lo menos desconhecido (Klaus \& Kennel, 1992; Raphael-Leff, 1991; Szejer \& Stewart, 1997), e assim facilitar o encontro com o bebê real (Brazelton \& Cramer, 1992). Ademais, caso o sexo do bebê não corresponda ao desejado pelos pais, este luto pode começar a ser elaborado (Szejer \& Stewart, 1997).

O nome também é compreendido como um parâmetro de antecipação do bebê e é a partir também desta escolha que o bebê torna-se mais real e assume mais o seu lugar enquanto um ser autônomo (Brazelton, 1992; Szejer \& Stewart, 1997). O nome escolhido pode refletir muito das expectativas depositadas no bebê e, inclusive, remeter ao significado deste para os pais (Szejer, 1999). O nome influencia na qualidade da interação da mãe com o bebê, ou seja, a escolha de um nome contribui para que as "conversas" da mãe com o bebê fiquem mais personificadas (Raphael-Leff, 1997).

A percepção materna dos movimentos fetais é considerada um grande marco na gravidez, pois faz com que a mãe sinta o feto como mais real e personificado, e incrementa, por isso, as expectativas referentes a ele. É a partir da maneira como são percebidos estes movimentos que as gestantes vão atribuindo características de temperamento ao bebê, além de expressarem que a interação passou a ser recíproca, e elas podem até compreender certas mensagens dos filhos (Maldonado, 1997; Raphael-Leff, 1997; Szejer \& Stewart, 1997).

O bebê anuncia, então, sua existência no interior dos pais muito antes do nascimento e os projetos e expectativas que envolvem a sua chegada preparam o lugar para acolhê-lo. Os aspectos concernentes a estas expectativas são diversos e importantes de ser compreendidos, pois são palavras que preparam o espaço do bebê, e, portanto, participam da relação após o nascimento. Diante do exposto acima, o objetivo deste estudo foi verificar as expectativas e os sentimentos das gestantes em relação ao seu bebê.

\section{Método}

\section{Participantes}

Participaram deste estudo 39 gestantes primíparas, no último trimestre de gestação, sem problemas de saúde, com idades entre 19 e 37 anos $(M=26$ anos; $D P=5,6$ anos $)$. Todas viviam com o pai do bebê. As participantes eram de níveis sócio-econômicos variados e residiam na região metropolitana de Porto Alegre. Em termos de escolaridade, as gestantes variaram entre primeiro grau incompleto $(2,6 \%)$ e completo $(7,7 \%)$, segundo grau incompleto $(2,6 \%)$ e completo $(35,9 \%)$, superior incompleto $(17,9 \%)$ e completo $(33,3 \%)$. Houve uma variação similar em termos do status ocupacional da profissão das gestantes, variando de profissões de "baixo status" (43,5\% das mães estavam em profissões classificadas de 1 a 4 na escala de Hollingshead, 1975), "status médio" (23\% em profissões classificadas de 5 a 6), e de "alto status" (33,3\% em profissões classificadas de 7 a 9). A amostra foi selecionada dentre os participantes de um projeto maior intitulado "Estudo Longitudinal de Porto Alegre: Da Gestação à Escola” (Piccinini, Tudge, Lopes \& Sperb, 1998). Esta pesquisa acompanha, aproximadamente, uma centena de famílias, com várias configurações familiares (casados, recasados, solteiras), de diferentes idades (jovens e adultos), com escolaridades e níveis sócio-econômicos variados ${ }^{4}$. O contato inicial para participar do projeto longitudinal foi feito com a gestante no terceiro trimestre de gestação, em hospitais da rede pública de Porto Alegre, postos de saúde, anúncios em jornais e indicação.

\section{Procedimentos}

No primeiro contato com as gestantes foram explicados os objetivos do estudo e, com aquelas que concordaram em participar, foi assinado o Consentimento Informado e realizada a Entrevista de contato inicial (GIDEP, 1998a) e a Entrevista de dados demográficos (GIDEP, 1998b). A primeira entrevista, usada para fins de recrutamento, buscava investigar algumas características demográficas, bem como

4 Além de crianças sem problemas de saúde, também foram acompanhadas crianças adotadas e crianças portadoras de doença crônica e Síndrome de Down. 
se a gestante era primípara, sua idade gestacional, seu estado de saúde. Uma vez atendidas as características exigidas para participar do estudo, realizava-se a segunda entrevista, usada para se obter informações demográficas adicionais, tais como: escolaridade, estado civil, ocupação, religião e grupo étnico.

Em seguida, era combinado um encontro na residência do casal, quando a gestante era solicitada a responder à Entrevista sobre a gestação e as expectativas da gestante (GIDEP, 1998c). Esta entrevista, semi-estruturada, era composta de oito conjuntos de questões relacionadas tanto ao bebê como à maternidade e examinava, por exemplo, as percepções da gestante em relação ao planejamento da gravidez, sua aceitação, seu estado de humor predominante durante a gestação e a gravidez no contexto da relação com o pai do bebê e demais membros de sua família. Além disso, investigavam-se as percepções e fantasias da gestante sobre o bebê e a maternidade. Para fins do presente estudo foram consideradas apenas as questões relacionadas ao bebê. Cada tópico investigado era apresentado inicialmente à gestante em forma de uma questão ampla (ex.: Eu gostaria que tu me falasses sobre o teu bebê). Caso a resposta da gestante não fosse muito explícita, eram então usadas outras questões que ajudavam a esclarecer os tópicos investigados (ex.: $O$ que tu já sabes sobre o bebê?; Tu já sabes o sexo do bebê?; Vocês já pensaram num nome para o bebê? Quem escolheu? Algum motivo para a escolha do nome?).

\section{Resultados}

Análise de conteúdo (Bardin, 1977; Laville \& Dionne, 1999) foi utilizada para se examinar as expectativas e sentimentos das gestantes sobre o bebê. Para fins de análise foram criadas cinco categorias temáticas que examinavam as expectativas e sentimentos quanto: 1) ao sexo do bebê; 2) ao nome do bebê; 3) às características psicológicas do bebê; 4) à interação mãe-bebê; 5) à saúde do bebê. Estas foram baseadas na literatura (Raphael-Leff, 1997; Stainton, 1985; Szejer \& Stewart, 1997) e nas próprias respostas das gestantes à entrevista. Dois dos autores do presente estudo classificaram separadamente os relatos das mães em cada categoria e subcategoria e, em casos de discordância, usou-se um terceiro juiz. A seguir, serão apresentadas e discutidas as categorias temáticas, exemplificando com verbalizações ilustrativas das próprias mães. No final de cada categoria apresenta-se uma tabela com a distribuição das respostas das gestantes em cada subcategoria.

\section{Expectativas e sentimentos quanto ao sexo do bebê}

Esta primeira categoria temática se refere às expectativas e aos sentimentos com relação a ter um filho ou uma filha e o quanto isto teria implicações para o relacionamento da díade. Os relatos das mães foram classificados em três subcategorias: crenças quanto ao sexo do bebê, desejo quanto ao sexo do bebê e, implicações quanto ao sexo para os sentimentos da gestante e relacionamento com o bebê.

Com relação às crenças sobre o sexo do bebê, foram tomadas separadamente as entrevistas das gestantes que já tinham a confirmação do sexo do bebê $(n=36)$ e as das gestantes que ainda não tinham esta informação $(n=3)$. Nas verbalizações das gestantes que já sabiam o sexo do bebê, foi referida uma crença definida de que o bebê fosse de determinado sexo: "sabe que eи acho que a mãe deve ter um sexto sentido, porque eu sempre, pra ver nome, pra ver tudo, eu sempre dizia que era um menino". ${ }^{5}$ As gestantes demonstraram, também, que suas crenças variaram ao longo da gestação, por vezes esperando um menino e outras uma menina e vice-versa: "vinha muito que era menina, eu sempre imaginava que era menina, depois imaginei que era tanto um filho homem que não conseguia me imaginar sem ele". Houve, ainda, relatos de gestantes que não revelaram qualquer crença quanto ao sexo do bebê: "não, a gente não tinha tendência para nenhum lado (...) mas eu realmente nunca manifestei, nem pensei”.

Em relação aos desejos das gestantes quanto ao sexo do bebê, as mães manifestaram uma clara preferência por um determinado sexo: "eu sempre queria, sabia que era menina. Aí quando a gente fez a eco, assim que o médico disse, né que era menina, ah, eu fiquei louca de faceira, né?" O desejo delas foi expresso também de forma associada ao desejo do pai do bebê para determinado sexo, demonstrando que sua satisfação era que o desejo do pai fosse confirmado: "eи fiquei feliz, mas de repente mais por ele [marido], porque ele estava querendo um menino e para mim não fazia diferença se fosse menino ou menina”. Percebeu-se, ainda, uma necessidade das mães de se manterem imparciais, ou seja, de não revelarem seu desejo quanto a um determinado sexo para o bebê: "acho que no fundo, no fundo, eu queria um guri, sabe. Mas eu não dava o braço a torcer por aquela coisa, não, não vou dizer que é um guri ou que é uma guria, porque se não vão dizer: 'ah, vai rejeitar'”. Além disto, as gestantes demonstraram se sentirem culpadas quando chegaram a investir em um bebê de determinado sexo que não se confirmou:

Eu sempre achava que era menino (...) comprei mais azul. Mas aí quando a gente fez a ultra-sonografia com cinco meses, parecia que era uma menina, foi uma coisa assim, mil perdões.

E pedi desculpas a ela, e ela eu acho que aceitou.

Com relação às implicações do sexo do bebê nos sentimentos das gestantes e na futura relação com o bebê, o sexo foi apontado como trazendo implicações para o papel/lugar que ele já ocupa na família: "é só mulher lá em casa, acho que é só por isso a minha vontade de ter um filho homem”. As gestantes referiram que a correspondência do sexo do bebê com o genitor do mesmo sexo podia acarretar no bebê semelhanças físicas ou de temperamento: "não sei se é porque ele é homem, né, vai ser homem. Mas imagino que tenha bastante coisas parecidas com ele". Sentimentos de exclusão também foram manifestados pelas gestantes, quando entendiam que o sexo do bebê podia ser determinante de uma relação pai-bebê mais intensa:

A gente sempre quer que seja mais amigo, assim, da gente, seja mais companheiro, ainda mais que vai ser guri,

5 As falas de cada gestante foram separadas por ponto e vírgula. Não foram usadas falas de uma mesma gestante para ilustrar uma mesma subcategoria. 
né, aí já tem mais medo, assim, de que ele seja mais amigo do pai, não dê tanta importância para a mãe.

O conhecimento do sexo (feminino) foi citado como uma possibilidade de desenvolver mais a feminilidade das gestantes "quando eu soube que era menina eu também gostei (...) achei que eu vou pensar mais na feminilidade, eu sempre fui uma menininha-guri quando era pequena". As gestantes referiram, ainda, que, conforme o sexo do bebê, diferenciariam as práticas educativas do bebê: "se for menino, é porque ele [o marido] quer sair pra jogar bola, se deixar vai passar o dia inteiro na rua, não vai ficar nem preocupado, mas se for guria, não vai poder passar nem do portão".

Nas verbalizações das gestantes que não tinham a confirmação do sexo do bebê, algumas particularidades apareceram. Por exemplo, de um lado foi salientada uma expectativa definida: "eu não sei porque, eu prefiro, mas eu nem sei (...) eu acho que vai ser uma menina"; assim como o desejo de saber o sexo do bebê, "eи gostaria muito, eи sou bem curiosa, essa semana eu vou fazer outra, aí pode ser que eu consiga". O desejo de saber o sexo do bebê foi relacionado à necessidade de nomeá-lo, torná-lo mais concreto:

Às vezes eu chamo de minha filha, às vezes de meu filho, aí eu digo não é meu filho, meu bebê, aí eu chamo ele de bebê, porque eu não sei o que é ainda, eu não sei o sexo, não posso chamar.

A Tabela 1 apresenta as porcentagens de ocorrências para a categoria Expectativas e sentimentos quanto ao sexo do bebê. Como pode ser observado, em relação à crença quanto ao sexo do bebê, a maioria das gestantes tinha uma crença definida de que o bebê seria de determinado sexo (53\%) antes mesmo de saberem seu sexo, seguido de algumas que manifestaram uma crença variada (14\%) ao longo da gestação. Poucas foram as gestantes que não verbalizaram nenhuma crença sobre o sexo de seu bebê (11\%). Quanto ao desejo de o bebê ser de determinado sexo, um número expressivo

Tabela 1. Porcentagem de ocorrências para a categoria Expectativas e sentimentos quanto ao sexo do bebê envolvendo as gestantes que já conheciam o sexo do bebê $(n=36)$

\begin{tabular}{llr}
\hline Quanto ao sexo do bebê & $\begin{array}{r}\text { Número de } \\
\text { gestantes * }\end{array}$ \\
\hline Crenças & $\begin{array}{l}\text { Definida antes da ultra- } \\
\text { sonografia }\end{array}$ & $53 \%(19)$ \\
& Variou ao longo da gestação & $14 \%(5)$ \\
& Sem crença definida & $11 \%(4)$ \\
\hline Desejos & Desejo da própria gestante & $44 \%(16)$ \\
& Necessidade de imparcialidade & $22 \%(8)$ \\
& $\begin{array}{l}\text { Desejo relacionado ao pai do } \\
\text { bebê }\end{array}$ & $17 \%(6)$ \\
\hline Implicações & $\begin{array}{l}\text { Identificação por } \\
\text { correspondência de sexo }\end{array}$ & $25 \%(9)$ \\
& Papel/lugar na família & $22 \%(8)$ \\
& $\begin{array}{l}\text { Diferenciação nas práticas } \\
\text { educativas }\end{array}$ & $17 \%(6)$ \\
& Sentimento de exclusão & $11 \%(4)$ \\
& $\begin{array}{l}\text { Desenvolvimento da } \\
\text { feminilidade }\end{array}$ & $3 \%(1)$ \\
\hline
\end{tabular}

$\overline{\text { Nota } * \text { Cada gestante pode ter apresentado respostas classificadas em mais }}$ de uma categoria. de gestantes (44\%) referiu suas próprias preferências por um dos sexos, enquanto $22 \%$ mantiveram-se imparciais quanto a este desejo. $\mathrm{O}$ desejo de algumas gestantes (17\%) apareceu relacionado ao desejo do pai do bebê. As implicações do sexo do bebê nos sentimentos das gestantes e na futura relação com ele apareceram mais ligadas à identificação por correspondência de sexo (25\%), seguida do papel/lugar que o bebê ocupará na família (22\%) e pela diferenciação das práticas educativas (17\%). Outras implicações apresentaram uma ocorrência mais baixa: $11 \%$ das gestantes referiram sentimento de exclusão por conta de o sexo do bebê tornar mais próxima a relação dele com o pai e, $3 \%$ manifestaram que a partir do sexo do bebê poderiam desenvolver mais sua feminilidade.

\section{Expectativas e sentimentos quanto ao nome do bebê}

Esta segunda categoria diz respeito aos diversos aspectos que envolveram a escolha e o significado do nome do bebê para a relação mãe-bebê. Os relatos das gestantes foram classificados em três sub-categorias relacionadas às razões para a escolha: características do próprio nome ou o que lembra/remete, gosto pelo nome, características que esperam do bebê e, implicações para a relação com $o$ bebê. As gestantes referiram que a escolha do nome ocorreu em função das características do próprio nome ou pelo que este lembrava ou remetia, incluindo pessoas que eram admiradas pelo casal: "eи quero um nome que não seja um nome comum, vamos dizer assim, quero chamar pela minha filha e ela saber que é ela, mesmo que tenha mil e uma". O nome também foi escolhido pelo fato de as gestantes gostarem daquele nome específico: "não tinha motivo especial, acho que era um nome assim, que a gente gostava”. Alguns sentimentos expressos em relação ao nome do bebê foram relacionados com características que os pais esperavam de seus filhos no futuro: "eu acho um nome muito forte, é um nome pomposo, é um nome de rei, pra mim vai ser um grande homem, vai ser uma pessoa muito importante, é o que eu quero". A escolha do nome do bebê foi mencionada também como instaurando uma relação mais próxima com o feto: "depois que a gente escolheu este nome, a gente começou a se relacionar muito com a barriga".

A Tabela 2 apresenta as porcentagens de ocorrências para a categoria Expectativas e sentimentos quanto ao nome do bebê. Percebe-se que as expectativas e os sentimentos da maioria das gestantes em relação ao nome do bebê apareceram ligados às características do próprio nome e ao que este

Tabela 2. Porcentagem de ocorrências para a categoria Expectativas $e$ sentimentos quanto ao nome do bebê $(n=39)$

\begin{tabular}{lr}
\hline \multicolumn{1}{c}{ Quanto ao nome do bebê } & $\begin{array}{c}\text { Número de } \\
\text { respostas * }\end{array}$ \\
\hline $\begin{array}{l}\text { Características do próprio nomeou pelo que } \\
\text { lembra/remete }\end{array}$ & $51 \%(20)$ \\
Características que esperam do bebê & $10 \%(4)$ \\
Implicações para a relação com o bebê & $5 \%(2)$ \\
\hline
\end{tabular}

Nota* Cada gestante pode ter apresentado respostas classificadas em mais $^{*}$ de uma categoria. 
lhes lembrava ou remetia (51\%). Outras mães escolheram o nome do bebê justificando que gostavam daquele nome $(38 \%)$. Algumas gestantes (10\%) expressaram que o nome para elas relacionava-se às características que esperavam do bebê e, duas gestantes $(5 \%)$ revelaram uma relação mais próxima com o bebê a partir da escolha do nome.

\section{Expectativas e sentimentos quanto às características psicológicas do bebê}

Esta terceira categoria diz respeito às impressões e desejos quanto às características psicológicas imaginadas para o bebê. As falas das gestantes foram classificadas em quatro subcategorias: semelhante aos genitores, impressões atuais e o futuro bebê, desejos e, impacto do estado emocional da gestante.

Com relação às semelhanças aos genitores, as gestantes relacionaram as características psicológicas de seu bebê com as características psicológicas dela ou do pai: "se for parecida comigo, ela vai ser mais calma, já ele é mais agitado", ou com a combinação das características psicológicas dos dois: "eu acho que de repente ele vai ser brabo, porque nós dois somos brabos". O desejo das gestantes de que o bebê tivesse determinadas características psicológicas também contribuiu para que elas construíssem uma representação do bebê: "então eu acho que ele vai ser mais quietinho, porque eu quero que ele seja mais quietinho".

As impressões atuais que a gestante já tem sobre o seu bebê foram também citadas como indicadoras de suas futuras características psicológicas. As impressões foram baseadas nos movimentos fetais: "se as características psicológicas for o que ele está aparentando na barriga vai ser super ativo" e na observação do bebê na ultra-sonografia "acho que ela vai ser bem geniosa, que nem eu, [pois] na eco ela estava com o bracinho assim, com a mão fechada. Então a vó vive dizendo que ela já é bem mandona, já está lá assim, de mão fechada".

As características psicológicas do bebê também foram relacionadas ao desejo das gestantes por um determinado tipo de temperamento: "então eu acho que ele vai ser mais quietinho, porque eu quero que ele seja mais quietinho". Por fim, foi mencionado o eventual impacto do estado emocional materno nas características psicológicas do bebê. Para algumas gestantes o seu estado emocional seria determinante para as características psicológicas de seu bebê: "eu imagino que ele seja tranqüilo, eи acho pelo meu estilo de vida, eu procuro não me envolver com esses problemas emocionais nesse período".

A Tabela 3 apresenta as porcentagens de ocorrências para a categoria Expectativas e sentimentos quanto às características psicológicas do bebê. A sub-categoria com maior destaque relaciona-se à crença de que as características psicológicas do bebê serão semelhantes às dos genitores (59\%). Em segundo lugar, apareceram os relatos de que as impressões atuais sobre o bebê (31\%) baseadas especialmente no tipo de movimentos fetais estariam relacionadas a determinadas características psicológicas do bebê. Um número menor de gestantes (18\%) referiu seus desejos como sendo um fator de grande influência na determinação das características psicológicas do bebê. Por fim, $15 \%$ das gestantes expressaram sua crença de que as características psicológicas do bebê seriam afetadas pelo seu próprio estado emocional materno durante a gestação.

Tabela 3. Porcentagem de ocorrências para a categoria Expectativas e sentimentos quanto às características psicológicas do bebê $(n=39)$.

\begin{tabular}{lc}
\hline \multicolumn{1}{c}{ Características psicológicas do bebê } & $\begin{array}{c}\text { Número de } \\
\text { gestantes* }\end{array}$ \\
\hline Semelhante aos genitores & $59 \%(23)$ \\
Impressões atuais e o futuro bebê & $31 \%(12)$ \\
Desejos & $18 \%(7)$ \\
Impacto do estado emocional da gestante & $15 \%(6)$ \\
\hline $\begin{array}{l}\text { Nota* Cada gestante pode ter apresentado respostas classificadas em mais } \\
\text { de uma categoria. }\end{array}$
\end{tabular}

\section{Expectativas e sentimentos quanto à interação mãe- bebê}

Esta quarta categoria temática refere-se ao modo como ocorre a interação mãe-bebê e as dificuldades das gestantes em estabelecer essa interação. As falas das gestantes com relação a esta categoria foram classificadas em quatro subcategorias: através delas mesmas, pelos movimentos fetais e, através de recursos externos e dificuldade de interagir.

Para algumas gestantes a sua interação com o bebê ocorria através delas mesmas, com base nas 'conversas' que elas tinham com o bebê. Durante estas conversas as gestantes disseram narrar acontecimentos, dividir sentimentos e explicar situações, como por exemplo: "desde agora já converso com ele 'Daqui a pouco, tu vai nascer, vai ser assim' (...) então eu converso com ele, não sei se adianta, eu acredito que sim". As gestantes também relataram que o toque na barriga era percebido como outro jeito de contatar o bebê: "essa coisa de passar a mão, até porque eu acho que é o único contato que tu tem, parece que é a coisa mais prática (...) dá a impressão de acalentar, me dá a impressão de ter". Os sonhos também foram citados como forma de interação, através da qual as gestantes expressavam a possibilidade de vivenciar a relação com o seu bebê: "eu sonhei várias vezes, como se tivesse passado a noite inteira com ele (...) deu a impressão que ele ficou a noite inteira comigo, com aquele contato assim".

A interação através dos movimentos fetais também foi relatada como uma forma de comunicação e acompanhamento do bebê, através das quais as gestantes contatavam o bebê e sentiam suas reações, sabendo sua posição na barriga, conhecendo seus hábitos e horários: "é preguiçosa pra acordar, eu acho que ela acorda meio tarde, eu vejo isso em função dos movimentos, claro". Além disso, as gestantes manifestaram que os movimentos eram uma forma de perceber a sua influência sobre o bebê (ele sentiria o que ela sentia): "quando eu fico muito ansiosa eu vejo que ele começa a reclamar aqui dentro, se mexe muito".

$\mathrm{Na}$ interação através de recursos externos, a ultra-sonografia foi citada como uma forma de contato mais real com o bebê, pela possibilidade de visualização, "na ultra-sonografia eu fico só olhando, porque por mim eu quero ficar 
Tabela 4. Porcentagem de ocorrências para a categoria Expectativas $e$ sentimentos quanto à interação mãe-bebê $(n=39)$

\begin{tabular}{llr}
\hline \multicolumn{2}{c}{ Quanto à interação mãe-bebê } & $\begin{array}{c}\text { Número de } \\
\text { gestantes* }\end{array}$ \\
\hline $\begin{array}{l}\text { Através delas } \\
\text { mesmas }\end{array}$ & Conversas & $59 \%(23)$ \\
& Toque na barriga & $28 \%(11)$ \\
& Sonhos & $8 \%(3)$ \\
\hline $\begin{array}{l}\text { Pelos movimentos } \\
\text { fetais }\end{array}$ & Comunicação & $46 \%(18)$ \\
\hline $\begin{array}{l}\text { Através de } \\
\text { recursos externos }\end{array}$ & Ultra-sonografia & $10 \%(4)$ \\
& Música & $23 \%(9)$ \\
\hline $\begin{array}{l}\text { Dificuldades de } \\
\text { interagir }\end{array}$ & Pertences do bebê & $13 \%(5)$ \\
\hline
\end{tabular}

Nota:* Cada gestante pode ter apresentado respostas classificadas em mais de uma categoria.

mais tempo, porque é o momento que tu tem de ficar quieta e ver se mexer, não se mexer". As gestantes relataram que a música também serviu como uma forma de interação com o bebê: "então tudo que a gente conversa com ela, ela está ouvindo e as musiquinhas que a gente coloca, ela tem 12 $C D$ 's ali dela, então a gente põe as musiquinhas dela”. O contato com os objetos que o bebê já possui foi outra maneira reconhecida pelas gestantes para interagir com o bebê: " $a$ gente deita na cama, o bercinho tá do lado, já tá o quarto todo arrumadinho, só esperando ele. A gente deita na cama e fica imaginando".

Por fim, houve relatos nos quais as gestantes manifestaram dificuldades para interagir com o seu bebê.

Pra mim, a minha filha é a minha barriga, não é o nenê, sabe, eu não tenho idéia do nenê, assim. Minha idéia que eu tenho de filha, por enquanto, é a barriga, não tem nada assim muito concreto de criança.

A Tabela 4 apresenta as porcentagens de ocorrências para a categoria Expectativas e sentimentos quanto à interação mãe-bebê. Como pode ser verificado nesta tabela, a maior parte das gestantes referiu que a interação com o bebê acontecia através de si mesmas, especialmente por meio de conversas $(59 \%)$, e pelo toque na barriga (28\%). Um menor número de gestantes $(8 \%)$ expressou que este contato acontecia através de sonhos com o bebê. A interação mãe-bebê através dos movimentos fetais como uma forma de comunicação da dupla também foi percebida por um grande número de gestantes (46\%). Um número menos expressivo de gestantes (10\%) reconheceu a interação quando seus comportamentos e sentimentos causavam alguma influência nas respostas do bebê. Dentre as formas de interação a partir de recursos externos, a ultra-sonografia foi a forma mais citada (23\%), seguida de músicas (13\%) e, por último, do contato com objetos do bebê (10\%). A dificuldade de interação com o bebê foi verbalizada somente por $2 \%$ das gestantes.

\section{Expectativas e sentimentos quanto à saúde do bebê}

Nesta quinta e última categoria temática foram incluídas as preocupações com relação ao bebê e a forma pela qual as gestantes se tranqüilizavam quanto as suas ansiedades. Os relatos das mães foram classificados em cinco subcategorias denominadas: preocupações próprias da gravidez, preocupações específicas, culpa e medo, tranqüilização através do pré-natal e, referiu não ter preocupações.

As gestantes evidenciaram preocupações próprias da gravidez, como, por exemplo, em relação à saúde fetal, referindo que estas faziam naturalmente parte do período gestacional: "a gente sempre pensa, não dá pra dizer que não, né, coisas com o nenê, de ser saudável ou não ser, qualquer mãe pensa". Foram citadas, também, preocupações mais específicas quanto à saúde do bebê, como a possibilidade de malformação fetal: "no início era a formação dos órgãos, como tava indo, daí tu fica meio preocupada, se o bebê tem alguma anomalia" ou de prematuridade, nesse caso pela possibilidade de causar complicações para a saúde do bebê: "tem que nascer na data certa pra tu não ficar na incubadora, ficar lá trancada, então tu te acalma aí, não vai nascer antes".

As gestantes relataram também sentimento de culpa, por medo de que algum comportamento seu, durante a gestação, pudesse ter causado algum mal ao bebê: "eu tenho receio, de não saber, um erro теи, um lapso теи еи causar algum problema com о теи".

Os recursos do pré-natal, tais como exames ou a opinião do médico, foram citados pelas gestantes como uma forma de tranqüilizá-las quanto à saúde do bebê: " $t u$ começa a pensar nos vários tipos de doenças, pode isso, pode aquilo, aí tu começa a fazer exames e tu vê que está tudo normal". Por fim, foram também encontrados relatos que demonstravam ausência de preocupações com a saúde do bebê: "não tem nada que me preocupe e não tenho assim, será que o meu filho é perfeito, não fico imaginando coisas, eu acho que ele é uma criança normal".

A Tabela 5 apresenta as porcentagens de ocorrências para a categoria Expectativas e sentimentos quanto à saúde do bebê. Pode-se observar nesta tabela que as preocupações das mães em relação à malformação do bebê foram as mais

Tabela 5. Porcentagem de ocorrências para a categoria Expectativas $e$ sentimentos quanto à saúde do bebê $(n=39)$

\begin{tabular}{lcc}
\hline \multicolumn{1}{c}{ Quanto à saúde do bebê } & $\begin{array}{c}\text { Número de } \\
\text { gestantes* }\end{array}$ \\
\hline $\begin{array}{l}\text { Preocupações } \\
\text { específicas }\end{array}$ & $\begin{array}{l}\text { Malformação } \\
\text { Prematuridade }\end{array}$ & $38 \%(15)$ \\
\hline $\begin{array}{l}\text { Tranquilização através } \\
\text { do pré-natal }\end{array}$ & $28 \%(11)$ \\
\hline $\begin{array}{l}\text { Preocupações próprias à } \\
\text { gravidez }\end{array}$ & $13 \%(5)$ \\
\hline $\begin{array}{l}\text { Culpa/Medo } \\
\text { Referiu não ter } \\
\text { preocupações }\end{array}$ & $5 \%(2)$ \\
\hline
\end{tabular}

Nota* Cada gestante pode ter apresentado respostas classificadas em mais de uma categoria. 
freqüentes (38\%). Somam-se a isto também as preocupações com a prematuridade (5\%). Já os recursos do pré-natal foram citados por um número razoável de gestantes $(28 \%)$ como passíveis de tranqüilizá-las quanto às suas preocupações. Um número menor de gestantes (13\%) expressou sua crença de que as preocupações são inerentes ao processo gestacional. Outras expectativas e sentimentos concernentes à saúde do bebê apareceram numa freqüência bastante baixa, como não ter preocupações ( $8 \%$ ) e a culpa/medo de causar algum dano ao bebê (5\%).

\section{Discussão}

As cinco principais categorias utilizadas na análise das verbalizações das gestantes (sexo, nome, temperamento, interação e saúde) parecem estar a serviço, na representação materna, "de dar mais identidade" ao bebê durante a gestação. Pode-se pensar que imaginar, interagir, acreditar, preocuparse são atitudes que revelam a existência de um vínculo com o bebê, o que permite nomeá-lo e torná-lo mais real. Desde o início da gravidez é estabelecida uma relação imaginária da mãe com o bebê, a qual fica representada por um corpo imaginado possuidor de todas as caracterizações necessárias para a completude de um corpo (Aulagnier, 1990; 1994). As verbalizações que revelaram ausência de expectativas e sentimentos quanto a determinado aspecto do bebê tiveram uma ocorrência muito baixa, o que expressa uma tendência da mãe de necessitar construir já na gestação uma representação mental sobre o bebê. É como se "encontrar" com o bebê antes de seu nascimento, e por isso, os dados do presente estudo corroboram a literatura no sentido que a relação mãe-bebê começa no período pré-natal (Brazelton, 1987; Brazelton, 1988; Caron, 2000; Condom \& Corkindale, 1997; Müller, 1996; Stainton, 1985).

As participantes deste estudo foram entrevistadas no terceiro trimestre de gestação, quando a literatura aponta que haveria um desinvestimento das expectativas maciças do bebê imaginário, para ceder lugar ao bebê real (Caron \& cols., 2000; Stern, 1997). Contudo, o que aparece neste estudo é que pelo menos para algumas gestantes, os dados reais sobre o bebê parecem estar servindo de base para mais expectativas e sentimentos, ao invés de reduzi-las. Por exemplo, as impressões sobre o comportamento do bebê na barriga, baseadas nos movimentos fetais, foram usadas para imaginar seu temperamento; ou as imagens ultra-sonográficas foram usadas para interagir mais com o bebê; ou resultados do pré-natal foram usados para evitar maiores preocupações. Já para outras gestantes, os desejos e as fantasias inconscientes pesam mais para construir a representação da imagem mental do bebê, como, por exemplo, quando imaginam as características psicológicas de acordo com o seu desejo de que o bebê seja de determinada maneira. Assim, contrariando o que se esperaria com base na literatura, pode-se dizer que o investimento do bebê imaginário não parece ainda ter sido reduzido para todas as participantes do presente estudo e, ao mesmo tempo, para outras se percebe que os dados de realidade foram absorvidos nas suas representações sobre o bebê. Sobre a perda do bebê imaginado, Caron (2000) refere que esta representação da mãe durante a gestação vai perdurar no tipo de relacionamento que se estabelecerá com o seu bebê da realidade. Essa personificação do bebê, ou construção mental do corpo imaginado (Aulagnier, 1990), é um processo tão intenso que muitas vezes continua se superpondo ao bebê da realidade. Partindo dos resultados do estudo, pode-se dizer que, no terceiro trimestre de gestação destas mulheres, as expectativas ligadas à fantasia e aquelas baseadas em dados reais coexistiram na formação da representação mental sobre o bebê. Pode-se supor, então, que este período do ciclo gravídico se constituiu em um momento particular de transição entre o bebê imaginário e o real na representação mental materna, à medida que algumas gestantes estavam mais ligadas ao primeiro que ao segundo e vice-versa. Porém, não é possível afirmar que esta transição findará após o nascimento do bebê.

Quanto ao sexo, especificamente, as gestantes, em geral, expressaram uma crença de que o bebê fosse de determinado sexo, o que vai ao encontro do que sugerem Klaus e Kennel (1992) ao afirmarem que mesmo não conhecendo o sexo do bebê, os pais sempre têm uma idéia interiormente formulada sobre este. A maior parte das gestantes reconheceu ter uma preferência quanto a um dos sexos, embora sendo todas elas primíparas, contrariando alguns achados que entendem que entre primíparas haveria uma tendência a uma aceitação incondicional do sexo do bebê e, por isso, não se preocupariam com esse dado (Villeneuve \& cols., 1988; Wu \& Eichmann, 1988). Seguindo esta tendência, algumas gestantes do presente estudo demonstraram preocupação de não manifestar preferência por determinado sexo, o que pode ser explicado por Brazelton (1992) como um temor da mãe de prejudicar o bebê. Pode-se também dizer que essa necessidade de manterse imparcial quanto a este desejo visava preservar a qualidade do vínculo mãe-bebê, preparando a gestante para o encontro com o bebê real. A preferência do pai do bebê por um dos sexos foi reconhecida por algumas participantes como sendo também sua. Stern (1999) aponta que em virtude do amor da mãe pelo companheiro, e pela escolha dele para ser o pai do seu filho, há um desejo de oferecer-lhe o seu produto mais precioso. Além disso, o apoio emocional à gestante se constitui em uma importante função atribuída ao pai (Klaus \& Kennell, 1992). Assim, a aceitação do bebê pelo pai é um fator fundamental para o estabelecimento e para a qualidade do apego da mãe ao bebê. Pode-se pensar, então, que desejar a realização do desejo do pai quanto ao sexo do bebê pode servir como uma garantia da continuidade do seu amor e do cumprimento da paternidade.

O sexo do bebê trouxe implicações não só para as expectativas e sentimentos das mães como para a relação destas com o bebê. Destacam-se, neste contexto, as expectativas de que o bebê se parecesse com o genitor do mesmo sexo, ou que dependendo do sexo do bebê, este teria uma diferenciação nas práticas educativas futuras. Estas parecem ser idéias decorrentes tanto de concepções sociais sobre o masculino e feminino, como de conteúdos inconscientes da própria gestante. Maldonado (1997) aponta que, muitas vezes, o desejo por um determinado sexo está associado a estereótipos sociais, como, por exemplo, o fato de acreditar-se que menina é mais parecida com a mãe e o menino é mais companheiro do pai, ou que a menina é mais fácil de educar do que o menino. Além disso, sabe-se que com a definição de papéis sexuais vivenciamos diferentes estruturações de 
aparelho psíquico, passando por diferentes identificações. Estas são vivências bastante precoces que deixam marcas essenciais no psiquismo (Freud, 1926/1969). Assim, as repercussões sobre o sexo do bebê, verbalizadas pelas gestantes deste estudo, parecem ter relação também com suas vivências anteriores e com seus próprios pais. Esta última consideração teórica se adequa à compreensão do sentimento de exclusão de algumas gestantes que, ao saberem o sexo do bebê, enfatizaram que isto levaria a uma maior proximidade do bebê com o pai. O sexo do bebê também foi citado como facilitador do desenvolvimento da feminilidade da própria gestante, endossando as idéias de Maldonado (1997) de que o sexo do bebê pode levar a gestante a sentir sua feminilidade ameaçada ou intensificada.

O nome do bebê, além de ter possibilitado uma relação mais próxima com ele, uma vez que fala nitidamente da identidade deste novo ser, revelou expectativas conscientes e inconscientes dos pais. Estes achados corroboram a literatura, que aponta que o nome revela muitas das expectativas depositadas no bebê (Szejer, 1999), além de influenciar na interação mãe-bebê, na medida em que este é visto como mais personalizado (Raphael-Leff, 1997). Para várias gestantes, a escolha do nome estava associada ao que ele lembrava ou remetia, com destaque para aspectos transgeracionais, que acabaram aparecendo com escolhas de nomes de pessoas que foram significativas no passado. Pode-se pensar que o bebê recebendo um nome que remeta a algo conhecido, sejam pessoas, situações, lugares, desejos ou expectativas, passa a ser menos estranho, e portanto menos ameaçador. Assim, é possível compreender, pelo menos em parte, por que as gestantes deste estudo referiram que depois desta escolha do nome do bebê, a relação mãe-bebê ficou ainda mais próxima; parece mais fácil aproximar-se de alguém, além de mais real, mais "familiar". Sobre essa maior proximidade, Szejer e Stewart (1997) apontam que o nome viabiliza um primeiro esboço de diálogo com o bebê. As verbalizações analisadas revelam, então, que o nome escolhido para o bebê parece revelar concretamente parte das expectativas, desejos e representações dos pais em relação àquele filho.

As expectativas quanto às características psicológicas do bebê apareceram muito ligadas à transgeracionalidade, fazendo com que muitas mães expressassem suas crenças de que o bebê seguiria "o jeito" de um ou dos dois genitores. $\mathrm{O}$ ato de desejar um filho pode ter origens numa mescla de razões conscientes e inconscientes e dentre as quais está o desejo de garantir a própria continuidade e de se auto-duplicar (Brazelton \& Cramer, 1992; Maldonado, 1997). Nesta categoria, é notável também que um número expressivo de gestantes atribuiu a expectativa de um determinado tipo de comportamento ao bebê, a partir de dados percebidos por elas durante a gestação, especialmente dos movimentos fetais. Assim, pensa-se que o bebê real não é conhecido somente após o nascimento e tampouco unicamente através da ultrasonografia. Dados reais do bebê vão sendo percebidos já durante o período gestacional e fazem parte, juntamente com os dados da fantasia, da representação mental da mãe sobre o bebê. Um número menor de participantes expressou seus desejos como um fator de possível influência nas características psicológicas do bebê. Percebe-se, em geral, que nestas mães o desejo transcende o imaginado, ou seja, é desde já esperado do filho que ele atenda não somente a uma expectativa ou uma crença e sim a um desejo da mãe que ele seja de determinada forma. Este desejo pode ser, em alguns casos, ligado a expectativas mais brandas e, após o nascimento do bebê, pode haver uma aceitação de seu temperamento genuíno; por outro lado, não se exclui a possibilidade de se tratarem de desejos e pressões "alienantes" (Cramer \& Palácio-Espasa, 1993). Como é assinalado na literatura, o papel negativo das expectativas ocupa o espaço da real identidade do bebê, que passa a assumir a carga maciça das projeções de seus pais. Algumas gestantes do presente estudo reconheceram que seu estado emocional durante a gravidez poderia ser transmitido para o feto, e poderia influenciar no seu temperamento. Este dado revela um sentimento de vínculo intenso entre a mãe e o bebê já durante a gestação. Para alguns autores, a mãe está envolvida em um diálogo com o feto, atrelando a ele seus níveis de atividades e seu estado emocional (Klaus \& Klaus, 1989).

Isto aparece ainda com mais clareza nos resultados referentes à categoria sobre interação mãe-feto, quando elas mencionam uma diversidade de maneiras através das quais se comunicam com os fetos. As conversas mãe-bebê apareceram como uma das formas preferidas pelas mães de entrarem em contato com seus bebês, seguida da comunicação através dos movimentos fetais. As conversas parecem servir tanto para que a mãe possa incluir, desde já, o bebê no seu dia-adia, informando-o sobre sua rotina, sobre novidades, como também para dividir com ele sentimentos mais íntimos, muitas vezes, ligados à maternidade. Elas podem explicar e justificar situações passadas ou futuras, podendo fazer da relação algo mais verdadeiro, real e sincero. Além disto, os movimentos, em geral, dão a idéia que a interação passou a ser recíproca, e que as mães podem até compreender certas mensagens dos filhos (Maldonado, 1997; Raphael-Leff, 1997; Szejer \& Stewart, 1997). Esses achados vão ao encontro dos estudos de Brazelton $(1987,1988)$ que revelaram que diversas gestantes percebem, desde muito cedo, que existe uma sintonia entre elas e o feto. $\mathrm{O}$ autor revela que, de fato, algumas experiências da mãe podem ser sentidas pelo feto, fazendo com que ele emita reações que funcionam como um feedback. Assim, principalmente no final da gravidez, as respostas fetais tornam-se bastante apuradas e a sintonia mãe-feto pode ser ainda mais aperfeiçoada. É importante lembrar que as gestantes do presente estudo estavam no terceiro trimestre de gestação, o que parece ter incrementado, então, essa percepção de comunicação. $O$ toque na barriga e a visualização pela ultra-sonografia também foram descritos como meios de interação com o bebê por um número também significativo de gestantes. Pode-se pensar que a necessidade de contato físico, nesse momento, fica dirigida ao toque na barriga, que segundo Szejer e Stewart (1997), se torna uma linguagem na qual a pele é o mediador. Já a visualização do bebê através da ultra-sonografia não deixa de ser um recurso que também possibilita um contato íntimo: a mãe pode enxergar claramente o bebê. Sabe-se que as imagens deste exame aparecem rapidamente na tela, informando diversos elementos de uma só vez, o que provoca uma sobrecarga emocional na mãe (Fonseca \& cols., 2000). Segundo estes autores o exame contribui para que a gestante entre em contato com profundas expressões inconscientes que 
logo se ligam à representação mental dela sobre o bebê. A maioria dos estudos revela uma influência positiva da ultrasonografia na relação mãe-feto (Caccia, Johnson, Robinson \& Barna, 1991; Fletcher \& Evans, 1983; Kohn, Nelson \& Weiner, 1980). Estes autores sugerem que a ultra-sonografia possibilita que a gestante se apodere mais do seu papel de mãe, incremente seus sentimentos maternos, e perceba o feto como mais real e próximo. O exame tende a facilitar, então, a transição para a parentalidade, e intensificar a união pré-natal entre mãe e feto (Gomes, 2003). Por fim, algumas gestantes manifestaram a utilização de músicas, o contato com os objetos do bebê e os sonhos noturnos com o bebê como formas importantes de interação com ele. As preocupações das gestantes do presente estudo em relação à saúde do bebê foram mais enfocadas na possibilidade de ocorrência de uma malformação fetal, quando o confronto entre o bebê real e o bebê imaginário assume uma dimensão impactante (Klaus \& Kennell, 1992). A profunda perda que se instala na mãe devido ao diagnóstico de um filho malformado acarreta o que se chama de "ferida narcísica", afetando diretamente sua auto-estima, na medida que seu bebê é considerado como sendo sua extensão (Ramona-Thieme, 1995). Pode-se, por estas razões, compreender que o medo de uma malformação atinja de forma significativa as gestantes, que se deparariam com sua própria incapacidade de gerar um filho perfeito. $\mathrm{O}$ fato de, no presente estudo, as participantes referirem tranqüilidade diante dos resultados favoráveis dos seus prénatais, sugere que elas se sentiram "aprovadas no teste de qualidade". Por vezes, o fato de visualizar o feto e seus movimentos no exame de ultra-sonografia é, para algumas mães, suficiente para livrá-las do estado perturbador; porém, para outras, as fantasias de malformações fetais persistem (Milne \& Rich, 1981). Assim, algumas mães manifestaram que as preocupações em relação à saúde do bebê eram inerentes à gestação, não cessando completamente em nenhum momento deste período. Maldonado (1997) refere que as preocupações maternas com a saúde do bebê só findam no momento do parto, quando é comum que a gestante questione se está tudo bem com o bebê e se ele é normal. Por fim, algumas gestantes referiram ausência de preocupação em relação à saúde do bebê. É pertinente lembrar que a maneira como cada mãe vivencia o período gestacional depende de seu próprio mundo interno, de suas relações passadas e suas necessidades conscientes e inconscientes relacionadas àquele bebê (Maldonado, 1997; Raphael-Leff, 1997; Soulé, 1987; Szejer \& Stewart, 1997). Também foram poucas as manifestações de culpa e medo de ter causado algum dano ao bebê, o que pode ser justificado pelo momento final de gestação em que as mesmas se encontravam. Neste período, normalmente, a ameaça maior destes fatores já foi ultrapassada.

Os resultados do presente estudo apóiam a idéia de que no período pré-natal os pais já constroem a noção de individualidade do bebê, reconhecendo alguns de seus comportamentos e características temperamentais (Stainton, 1985). Ademais, desde muito cedo os pais estabelecem um modo costumeiro de interação com o feto. Esta intimidade, segundo o autor, se constitui através de informações, tais como, sexo, maneira de movimentar-se, e determinam a estruturação de um padrão de interação precoce entre pais e feto, que tende a continuar após o parto. Este estudo apontou a existência de uma relação materno-fetal bastante intensa, a qual é embasada especialmente nos sentimentos ou expectativas das gestantes sobre o sexo, o nome, as características psicológicas, a interação mãe-feto e as preocupações com a saúde do bebê. Os resultados sugerem que conhecer o bebê antes do nascimento, estar com ele, pensar sobre ele, imaginar suas características, traz implicações para a construção da representação do bebê, da maternidade e para a atual relação mãe-bebê.

Contudo, é importante atentarmos que esta postura de imaginar, pensar e estar com o bebê antes do nascimento é apenas uma das formas de se avaliar a proximidade do contato da gestante com o bebê. Assim, não se pode afirmar que aquelas gestantes que não expressem expectativas claras ou uma representação mental explícita sobre o bebê não estejam, de fato, se relacionando com seu bebê de forma próxima. Para ter esta visão mais definida, outros aspectos devem ser avaliados e considerados, respeitando que a maternidade é vivenciada de forma complexa e singular por cada mulher.

\section{Referências}

Aulagnier, P. (1990). Um intérprete em busca de sentido. São Paulo: Escuta.

Aulagnier, P. (1994). Nacimiento de un cuerpo, origen de una historia. Em Luis Hornstein (Org.), Cuerpo, historia, interpretación (pp. 117-170). Buenos Aires: Paidós.

Bardin, L. (1977). Análise de conteúdo. Lisboa: Edições 70.

Brazelton, T. (1987). O bebê: Parceiro na interação. Em T. Brazelton, B. Cramer, L. Kreisler, R. Schäppi \& M. Soulé. (1987). A dinâmica do bebê (pp. 9-23). Porto Alegre: Artes Médicas.

Brazelton, T. (1988). O desenvolvimento do apego. Porto Alegre: Artes Médicas.

Brazelton, T. \& Cramer, B. (1992). As primeiras relações. São Paulo: Martins Fontes.

Caccia, N., Johnson, J., Robinson, G. \& Barna, T. (1991). Impact of prenatal testing on maternal-fetal bonding: Chorionic villus sampling versus amniocentesis. American Journal Obstetric Gynecology, 165(4), 1122-1125.

Caron, N. (2000). O ambiente intra-uterino e a relação materno-fetal. Em N. Caron (Org.), A relação pais-bebê: Da observação à clínica (pp. 119-134). São Paulo: Casa do Psicólogo.

Caron, N., Fonseca, M., \& Kompinsky, E. (2000). Aplicação da observação na ultra-sonografia obstétrica. Em N. Caron (Org.), A relação pais-bebê: Da observação à clínica (pp. 178-206). São Paulo: Casa do Psicólogo.

Condom, J. \& Corkindale, C. (1997). The correlates of antenatal attachment in pregnant women. British Journal of Medical Psychology, 70(4), 359-372.

Cramer, B. \& Palácio-Espasa, F. (1993). Técnicas picoterápicas mãe/bebê. Porto Alegre: Artes Médicas.

Fletcher, J. \& Evans, M. (1983). Maternal bonding in early fetal ultrasound examinations. New England Journal of Medicine, 308, 392-393.

Fonseca, M., Magalhães, J., Papich, H., Dias, R. \& Schimidt, A. (2000). Ultra-sonografia em obstetrícia: Explorando um novo mundo. Em N. Caron (Org.), A relação pais-bebê: Da observação à clínica (pp. 97-118). São Paulo: Casa do Psicólogo.

Freud, S. (1969). Inibições, sintomas e ansiedade (M. A. M. Rego, Trad.). Em J. Salomão (Org.), Edição standard brasileira de 


\section{A. Piccinini e cols.}

obras completas de Sigmund Freud (Vol. 20, pp. 107-180). Rio de Janeiro: Imago (Originalmente publicado em 1926).

Gomes, A. (2003). A ultra-sonografia obstétrica e suas Implicações na relação mãe-feto: Impressões e sentimentos de gestantes com e sem diagnóstico de anormalidade fetal. Dissertação de Mestrado, Universidade Federal do Rio Grande do Sul, Porto Alegre.

Grace, J. (1984). Does a mother's knowledge of fetal gender affect attachment? MCN American Journal Maternal Child Nursing, 9, 42-45.

Grupo de Interação Social, Desenvolvimento e Psicopatologia (1998a). Ficha de contato inicial dados demográficos da gestante.Universidade Federal do Rio Grande do Sul, Porto Alegre.

Grupo de Interação Social, Desenvolvimento e Psicopatologia (1998b). Entrevista de dados demográficos da gestante. Universidade Federal do Rio Grande do Sul, Porto Alegre.

Grupo de Interação Social, Desenvolvimento e Psicopatologia (1998c). Entrevista sobre a gestação e as expectativas da gestante. Universidade Federal do Rio Grande do Sul, Porto Alegre.

Holligshead, A. (1975). Four factor index of social status. Manuscrito não publicado, Yale University.

Klaus, M. \& Klaus, P. (1989). O surpreendente recém-nascido. Porto Alegre: Artes Médicas.

Klaus, M., \& Kennel, J. (1992). Pais/bebê: A formação do apego. Porto Alegre: Artes Médicas.

Kohn, C., Nelson, A. \& Weiner, S. (1980). Gravida's response to realtime ultrasound fetal image. Journal of Obstetric, Gynecology and Neonatal Nursing, 9, 77-80.

Laville, C. \& Dionne, J. (1999). A construção do saber: Manual de metodologia da pesquisa em ciências humanas. Porto Alegre: Artes Médicas.

Maldonado, M. (1997). Psicologia da gravidez. Petrópolis: Vozes.

Milne, L. \& Rich, U. (1981). Cognitive and affective aspects of the responses of pregnant women to sonography. Maternal Child Nursing Journal, 10(1), 15-39.

Müller, M. (1996). Prenatal and postnatal attachment: A modest correlation. Journal Obstetric Gynecology Neonatal Nursing, 25(2), 161-166.
Piccinini, C. A., Tudge, J., Lopes, R. C. \& Sperb, T. (1998). Estudo longitudinal de Porto Alegre: Da gestação à escola. Projeto de Pesquisa, Universidade Federal do Rio Grande do Sul, Porto Alegre.

Ramona-Thieme, M. (1995). Becoming a mother: Research on maternal identity from Rubin to the present. New York: Spring Publishing.

Raphael-Leff, J. (1991). Psychological processes of childbearing. Londres: Chapman \& Hall.

Raphael-Leff, J. (1997). Gravidez: A história interior. Porto Alegre: Artes Médicas.

Raphael-Leff, J. (2000). Introduction: Technical issues in perinatal therapy. Em J. Raphael-Leff (Org.), 'Spilt milk' perinatal loss \& breakdown (pp. 7-16). Londres: Institute of Psychoanalysis.

Soifer, R. (1980). Psicologia da gravidez, parto e puerpério. Porto Alegre: Artes Médicas.

Soulé, M. (1987). O filho da cabeça, o filho imaginário. Em T. Brazelton, B. Cramer, L. Kreisler, R. Schappi \& M. Soulé (Orgs.), A dinâmica do bebê (pp. 132-170). Porto Alegre: Artes Médicas.

Stainton, M. (1985). The fetus: A growing member of the family. Family Relations, 34, 321-326.

Stern, D. (1997). A constelação da maternidade. Porto Alegre: Artes Médicas.

Stern, D. (1999). El nacimiento de una madre: Cómo la experiencia de la maternidad te cambia para siempre. Buenos Aires: Paidós.

Szejer, M. \& Stewart, R. (1997). Nove meses na vida da mulher. São Paulo: Casa do Psicólogo.

Szejer, M. (1999). Palavras para nascer: A escuta psicanalítica na maternidade. São Paulo: Casa do Psicólogo.

Villeneuve, C., Laroche, C., Lippman, A. \& Marrache, M. (1988). Psychological aspects of ultrasound imaging during pregnancy. Canadian Journal of Psychiatry, 33(6), 530-535.

Wu, J. \& Eichmann, A. (1988). Fetal sex identification and prenatal bonding. Psychological Reports, 63(1), 199-202.

Recebido em 12.04.2004

Primeira decisão editorial em 01.11.2004

Versão final em 09.11.2004

Aceito em 28.11.2004 